\title{
Absence of acidosis in the initial presentation of propionic acidaemia
}

\author{
J H Walter, J E Wraith, M A Cleary
}

Willink Biochemical Genetics Unit, Royal Manchester Children's Hospital, Pendlebury, Manchester M27 4HA $\mathrm{J} H$ Walter

J E Wraith

M A Cleary

Correspondence to: Dr J H Walter.

Accepted 23 January 1995

Table 1 Clinical presentation in 11 patients with propionic acidaemia

\begin{tabular}{lc}
\hline Symptom & $N=$ \\
\hline Poor feeding/vomiting & 10 \\
Jittery/fitting & 8 \\
Lethargy & 6 \\
Floppy & 6 \\
Weight loss/dehydration & 2 \\
Sepsis & 2 \\
\hline
\end{tabular}

\begin{abstract}
The clinical presentation and results of the initial biochemical and haematological investigations in 11 newborn term infants with propionic acidaemia are described. All patients had neurological symptoms. Only four had clinically important acidosis, but all had a raised blood ammonia. A diagnosis of propionic acidaemia should be considered in all newborn infants with unexplained neurological deterioration even in the absence of a metabolic acidosis.

(Arch Dis Child 1995; 72: F197-F199)
\end{abstract}

Keywords: propionic acidaemia, organic acidaemia, metabolic acidosis.

Propionic acidaemia (PA) is one of the most common inherited disorders of organic acid metabolism. ${ }^{1}$ The disease is caused by a deficiency in the mitochondrial enzyme propionyl CoA carboxylase and leads to an accumulation in propionic acid and other metabolites. ${ }^{2}$ The clinical phenotype is severe and most affected children present soon after birth. Those who do not die in the newborn period rarely survive beyond their first decade. ${ }^{34}$ The initial presentation in newborn infants is thought almost always to be characterised by a severe metabolic acidosis and it is this finding that usually suggests the diagnosis. We report our experience in which, in most patients presenting with PA, metabolic acidosis was either mild or absent.

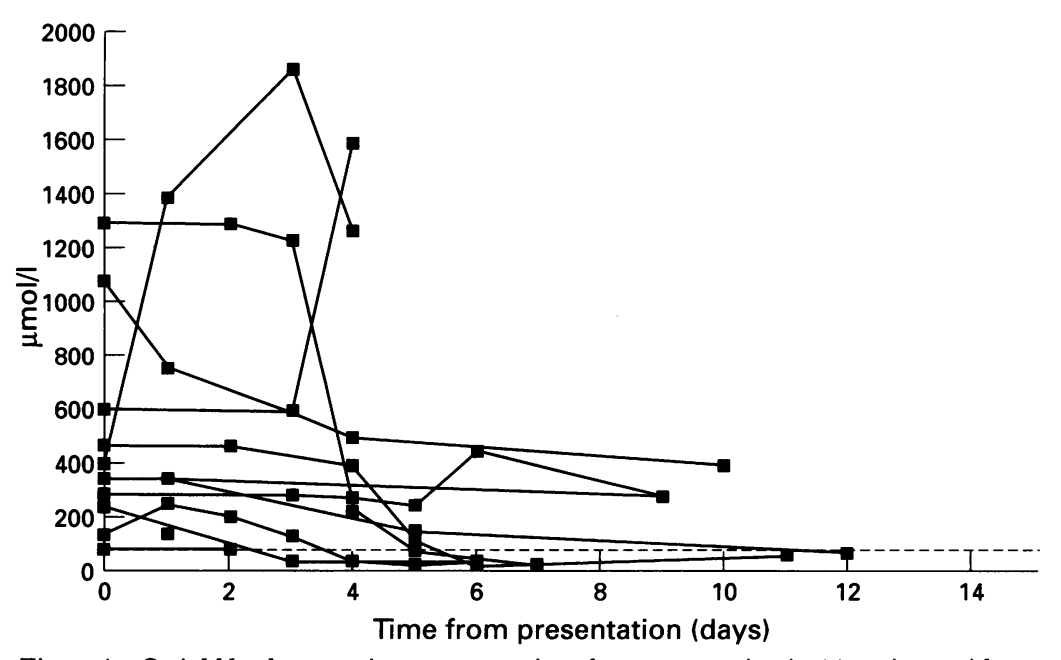

Figure 1 Serial blood ammonium concentrations from presentation in 11 patients with propionic acidaemia. The broken line represents the normal upper limit of $80 \mu \mathrm{mol}$.

\section{Methods}

Between 1986 and 1994, 11 newborn infants with PA, from nine families, were both diagnosed and had their clinical care provided by our unit. The diagnosis was based in 10 cases on finding characteristic metabolites in the urine on analysis by gas chromatography/ mass spectrometry and subsequently confirmed by assay of propionyl CoA carboxylase activity in leucocytes or cultured fibroblasts. One child, whose previous sibling had died from PA, was diagnosed prenatally by assay of propionyl CoA carboxylase in cultured amniocytes. All patients were of Asian origin and in most cases the parents were consanguineous.

A summary of the clinical features at presentation is given in table 1 . The median age at presentation was nine days, range one to 22 days. Neurological symptoms were prominent: all but one of the patients had poor feeding or vomiting and most were lethargic. Most were jittery or had frank convulsions. Axial hypotonia was often found on examination.

A summary of the biochemical and haematological abnormalities at initial presentation is given in table 2 . Serial measurements of blood ammonia, arterial $\mathrm{pH}$, and bicarbonate are shown in figures 1,2 , and 3 , respectively. Hyperammonaemia was found in all children. The median value for the ammonium measurement at the time of presentation was $350 \mu \mathrm{mol} / 1$ (range 84-1300). Two children had values above $1000 \mu \mathrm{mol} / \mathrm{l}$. Metabolic acidosis (bicarbonate of $<18 \mathrm{mmol} / \mathrm{l}$ ) was present in only four children at presentation. The median $\mathrm{pH}$ for the group as a whole was 7.39 (range $7 \cdot 11$ to $7 \cdot 52$ ). The median bicarbonate was $18.5 \mathrm{mmol} / \mathrm{l}$ (range 7.4 to $22.8 \mathrm{mmol} / \mathrm{l}$ ). Two patients were alkalotic and these were the children with ammonium concentrations in excess of $1000 \mu \mathrm{mol} / 1$. Hypocalcaemia, neutropenia, and thrombocytopenia were frequent, although these were often not present initially.

\section{Treatment}

All patients were treated with intravenous dextrose and electrolyte replacement. Five required assisted ventilation. Intravenous sodium benzoate $(250-500 \mathrm{mg} / \mathrm{kg} /$ day $)$ was used to treat hyperammonaemia in eight patients. Despite theoretical concerns regarding accumulation of benzoate within mitochondria ${ }^{3}$ we have found this to be a safe and effective treatment in patients with propionic acidaemia who have good renal function. 


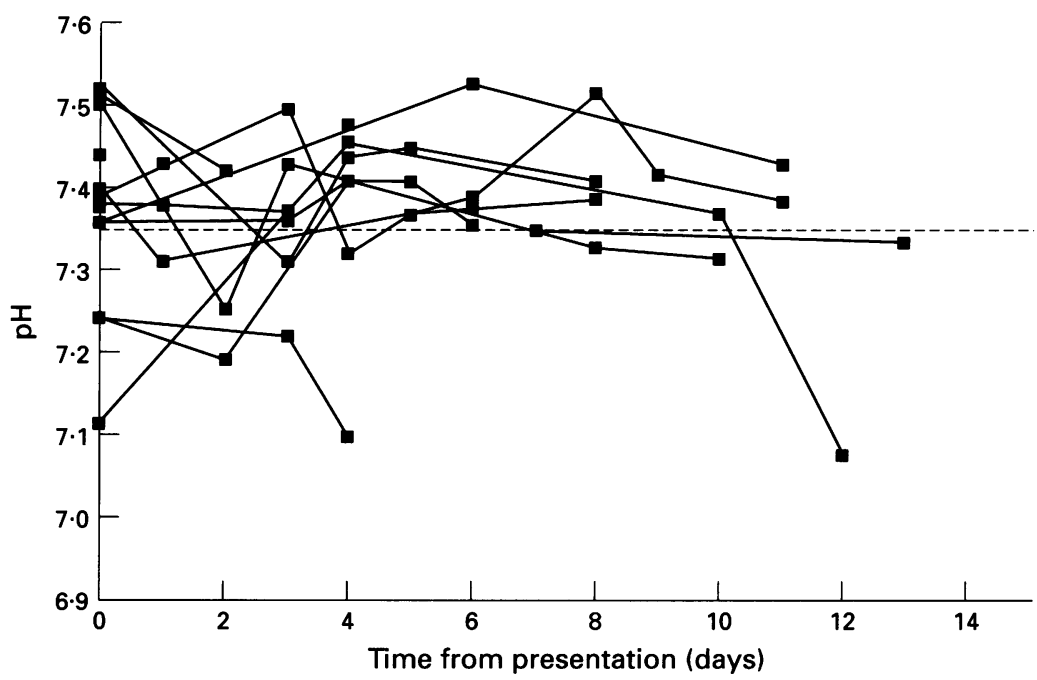

Figure 2 Serial arterial $p H$ values from presentation in 11 patients with propionic acidaemia. The broken line represents the normal lower limit of $7 \cdot 35$.

Two patients required peritoneal dialysis. Seven patients were treated with either oral or intravenous L-carnitine. All patients were initially treated with biotin, the co-factor for propionyl CoA carboxylase but none showed any biochemical response. Eight patients survived their initial illness and were subsequently discharged home.

\section{Discussion}

The early mortality for children with propionic acidaemia presenting in the newborn period is generally thought to be very high. ${ }^{5}$ However, with early diagnosis and intensive care support over two thirds of our patients survived. Although most of these children

Table 2 Biochemical and haematological abnormalities at presentation in 11 patients with propionic acidaemia

\begin{tabular}{lr}
\hline & $N=$ \\
\hline Hyperammonaemia $(>80 \mu \mathrm{mol} / \mathrm{l})$ & 11 \\
Hypocalcaemia $(<1.8 \mathrm{mmol} / \mathrm{l})$ & 4 \\
Metabolic acidosis $\left(\mathrm{HCO}_{3}<18 \mathrm{mmol} / \mathrm{l}\right)$ & 4 \\
Neutropenia $\left(\right.$ neutrophils $\left.<1 \times 10^{3} / \mathrm{mm}^{3}\right)$ & 3 \\
Thrombocytopenia (platelets $\left.<120 \times 10^{9} / \mathrm{l}\right)$ & 2
\end{tabular}

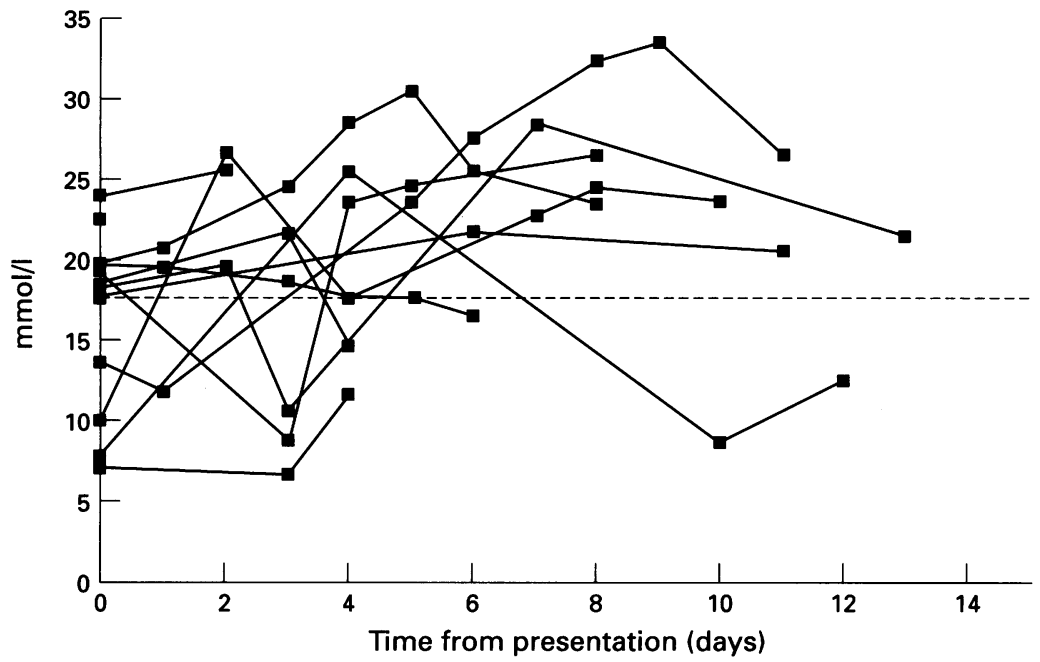

Figure 3 Serial blood bicarbonate concentrations from presentation in 11 patients with propionic acidaemia. The broken line represents the normal lower limit of $18 \mathrm{mmol}$. subsequently have had moderate to severe developmental delay, in keeping with other reported series, ${ }^{34}$ two children have shown normal development in the first year of life. Both had less than 5\% enzyme activity in vitro, but were not severely ill. One of these children underwent a liver transplant at 15 months with encouraging results (P J McKiernan, et al, abstract presented at 32nd Annual Symposium of the Society for the Study of Inborn Errors of Metabolism, Edinburgh, 1994). The other, whose sibling died at four weeks with severe hyperammonaemia and who was diagnosed prenatally and treated from birth, is now being assessed for liver transplantation. In order to offer children with this disorder any hope of long term survival without severe psychomotor retardation, it is important that the diagnosis is made and treatment started before severe metabolic decompensation occurs. Metabolic acidosis was not present in most of our patients at presentation. By contrast, hyperammonaemia was found in all of them. The accumulation of propionate and other acidic metabolites seems to have been sufficient to inhibit the urea cycle but not to cause clinically relevant acidosis.

Hyperammonaemia is also known to cause an alkalosis ${ }^{6}$ and this may have further reduced or delayed the onset of acidosis. DNA analysis had not been undertaken in these patients but their similar clinical phenotype and racial origin may indicate that they have the same mutation responsible for their disease.

Thrombocytopenia and neutropenia are known to occur in propionic acidaemia and are thought to be due to a direct toxic effect of propionic acid on bone marrow proliferation and maturation. ${ }^{7}$ Although most of our patients had low neutrophil (seven patients) and platelet counts (six patients) during the course of their illness, only a minority were neutropenic or thrombocytopenic at presentation. Similarly, serum calcium concentrations were low initially in only four patients but subsequently in nine.

In conclusion, the diagnosis of an organic acidaemia should be considered in all newborn infants with unexplained neurological deterioration even in the absence of acidosis. A low white cell count, platelet count, and low calcium may support such a diagnosis but may be normal at presentation. The recognition and treatment of hyperammonaemia is likely to be crucial in improving the early outcome for these patients and of particular importance if liver transplantation and, perhaps in the future, gene therapy ${ }^{8}$ are found to be an effective treatment for organic acidaemias.

1 Ogier H, Charpentier C, Saudubray JM. Organic acidemias. In: Fernandes J, Saudubray JM, Tada K, eds. Inborn metabolic diseases. Berlin: Springer-Verlag, 1990: Inborn meta.

2 Rosenberg LE, Fenton WA. Disorders of propionate and methylmalonate metabolism. In: Scriver CR, Beaude AL, Valle D, eds. The metabolic basis of inherited disease, 6th edn. New York: McGraw-Hill, 1989: 821-44. 
3 Leonard JV, Daish P, Naughten ER, Bartlett K. The management and long term outcome of organic acidaemias. agement and long term outcome of organic
f Inherit Metab Dis 1984; 7 (suppl 1): 13-17.

4 Surtees RA, Matthews EE, Leonard JV. Neurologic outcome of propionic acidemia. Pediatr Neurol 1992; 8: 333-7.

5 Rousson R, Guibaud P. Long term outcome of organic acidurias: survey of 105 French cases (1967-1983). F Inherit Metab Dis 1984; 7 (suppl 1): 10-12.

6 Walter $\mathrm{JH}$, Leonard JV. Inborn errors of the urea cycle. $\mathrm{Br}$ f Hosp Med 1987; 38: 176-83.

7 Stork LC, Ambruso DR, Wallner SE, et al. Pancytopenia in propionic acidemia: hematologic evaluation and studies of hematopoiesis in vitro. Pediatr Res 1986; 20: 783-8.

8 Lamhonwah AM, Leclerc D, Loyer M, Clarizio R, Gravel RA. Correction of the metabolic defect in propionic acidemia fibroblasts by microinjection of a full-length cDNA or RNA transcipt encoding the propionyl-CoA cDNA or RNA transcript encoding the propionyl-Co,

9 Wilkemeyer M, Stankovics J, Foy T, Ledley FD. Propionate metabolism in cultured human cells after overexpression of recombinant methylmalonyl CoA mutase: implications for somatic gene therapy. Somatic Cell and Molecular Genetics 1994; 18: 493-505. 